\title{
cmaJOPEN
}

\section{Prevalence of adverse childhood experiences among individuals aged 45 to 85 years: a cross-sectional analysis of the Canadian Longitudinal Study on Aging}

\author{
Divya Joshi PhD, Parminder Raina PhD, Lil Tonmyr PhD, Harriet L. MacMillan MD, \\ Andrea Gonzalez PhD
}

Abstract

Background: Population-level prevalence estimates for a broad range of adverse childhood experiences (ACEs), which are known to affect health across the lifespan, are currently unavailable in Canada. The purpose of this study was to estimate the prevalence of individual ACEs by sociodemographic factors among middle-aged and older adults.

Methods: Data for this cross-sectional analysis were obtained from the first follow-up (2015-2018) of the Canadian Longitudinal Study on Aging (baseline recruitment from 2011 to 2015). Participants included individuals aged 45-85 years and residing in the community in the 10 Canadian provinces. Exposure to ACEs was assessed using a retrospective, self-report questionnaire. Logistic regression was used to obtain the adjusted prevalence estimates of ACEs within groups formed by the sociodemographic characteristics and each variable was adjusted for all other sociodemographic variables.

Results: Of the 44817 participants in the first follow-up, 61.6\% (weighted) reported exposure to at least 1 ACE. Exposure to physical abuse (weighted prevalence of $25.7 \%$ ), intimate partner violence $(22.4 \%)$ and emotional abuse $(21.8 \%)$ were the most prevalent types of ACEs. Individuals younger than 65 years (born in 1950-1969), with no postsecondary education or education below a bachelor's degree, or with annual household income less than $\$ 20000$ reported greater exposure to ACEs. Reporting for many ACEs was higher among women and those of nonheterosexual orientation. Overall, British Columbia, Alberta, Manitoba, Ontario and Quebec reported relatively higher prevalence for several examined categories of ACEs.

Interpretation: Adverse childhood experiences were highly prevalent across all demographic groups with substantial heterogeneity in the distribution among the middle and older age population. The high prevalence of ACEs and their potential negative consequences on health and well-being emphasize the need to develop and promote trauma-informed care to assist individuals affected by ACEs.

rowing evidence suggests that adverse childhood experiences (ACEs) not only have developmental impacts but also increase the risk of additional stressors and are associated with impairment in physical, psychological and social health across the lifespan. ${ }^{1-8}$ Adverse childhood experiences are stressful and traumatic experiences of childhood that include exposure to maltreatment, such as abuse and neglect, and other household adversities, such as parental separation or poor parental mental health. ${ }^{1-2}$ Studies have shown a negative association between ACEs and various health outcomes, with research suggesting that ACEs may pose a threat to successful aging. ${ }^{1-9}$ Successful aging can be defined from various perspectives including but not limited to physical, psychological and social health, availability of resources, functioning and satisfaction with life. ${ }^{9}$

In addition to the direct effects on the exposed individual, ACEs have societal effects through lower productivity and increased use of health and social services. ${ }^{10,11}$ Although studies have evaluated the impact of ACEs, the population-level prevalence estimates for a broad range of ACEs including emotional abuse and neglect in Canada are lacking. Before examining associations, it is essential to gain an understanding of the burden and distribution of ACEs in the population.

The present study provides prevalence estimates of individual ACEs by sociodemographic characteristics among middle-aged and older adults in Canada. Addressing this gap in knowledge is important for social and health care providers and policy-makers to understand and improve health outcomes in aging populations, to develop and implement policies and programs to lower the prevalence of ACEs and related health outcomes, and to support the individuals who have experienced ACEs and their families.

\section{Competing interests: None declared.}

This article has been peer reviewed.

Correspondence to: Andrea Gonzalez, gonzal@mcmaster.ca CMAJ Open 2021. DOI:10.9778/cmajo.20200064 


\section{Methods}

\section{Study design and population}

Using data from the Canadian Longitudinal Study on Aging (CLSA), the current study describes the distribution of ACEs by sociodemographic factors in an aging population. The CLSA is a national, population-based longitudinal study examining health and aging. A stratified sample of 51338 men and women aged $45-85$ years residing in the community in the 10 Canadian provinces were recruited at baseline between 2011 and 2015. Details on the study design and methodology have been described previously; in brief, 3 sampling frames including Statistics Canada's Canadian Community Health Survey (CCHS) - Healthy Aging, provincial health care systems and random digit dialing of landline telephones were used to recruit participants into the CLSA cohort. ${ }^{12,13}$

The CLSA cohort has 2 components: the tracking cohort $(n=21241)$ and the comprehensive cohort $(n=30$ 097). Participants in the tracking cohort were recruited from the 10 provinces, and data were collected using questionnaires administered by computer-assisted telephone interviews. ${ }^{12,13}$ Participants in the comprehensive cohort were recruited from individuals residing within a $25-50 \mathrm{~km}$ distance from 1 of 11 data collection sites located in 7 provinces, and data were collected in-person through a computer-assisted interview and through more in-depth tests, physical measurements and biological specimens collected at the data collection sites. ${ }^{12,13}$ All participants provided information on demographic characteristics, lifestyle and behaviour, and social, physical, and psychological health and use of health services.

To date, the CLSA has had 2 follow-ups. In this study, we analyzed data from the first follow-up (2015-2018). Data collection included telephone interview, in-home, face-to-face interview or a questionnaire administered at a data collection site visit. The first follow-up included assessment of ACEs. ${ }^{12,13}$

\section{Measurement of ACEs}

At the first follow-up, adverse childhood experiences were measured using the short form of the Childhood Experiences of Violence Questionnaire (CEVQ) ${ }^{14,15}$ and the National Longitudinal Study of Adolescent to Adult Health Wave III questionnaire. ${ }^{16}$ Fourteen items selected from the CEVQ make up the CEVQ short form (these items are presented in Appendix 1, available at www.cmajopen.ca/content/9/1/ E158/suppl/DC1). ${ }^{15}$ All items referred to exposure before the age of 16 years.

Frequency and severity of exposure to childhood abuse, neglect and intimate partner violence were assessed on an ordinal scale (never, 1-2 times, 3-5 times, 6-10 times or more than 10 times) and subsequently dichotomized as presence or absence of exposure based on the CEVQ instructions..$^{15}$ Physical abuse was present if the participant reported being slapped on the face, head or ears, or hit or spanked with something hard 3 or more times; being pushed, grabbed or shoved, or having something thrown to hurt 3 or more times; or being kicked, bit or punched, or choked, burned or physically attacked in some other way 1 or more times. ${ }^{15}$
Sexual abuse was present if the participant reported being threatened, touched or forced into unwanted sexual activity 1 or more times. ${ }^{15}$ Emotional abuse was present if the participant reported parents or guardians swearing, saying hurtful or insulting things that made the participant feel unloved or unwanted 3 or more times. Participants were classified as being neglected if they reported their parents or guardians not having taken care of their basic needs. Childhood exposure to intimate partner violence was present if the participant reported seeing or hearing parents or guardians say hurtful things to each other 6 or more times, or seeing or hearing parents or guardians hit each other 3 or more times. ${ }^{15}$

Test reliability of the CEVQ has not been assessed in adults between the ages of 45 and 85 years. The 2-week test-retest reliability of the CEVQ short form (CEVQ-SF) in measuring physical and sexual abuse among youth were $\kappa=0.61$ and $\kappa=$ 0.91 , respectively. ${ }^{15}$ Kappa values for other forms of abuse and household adversity ranged between 0.66 and $0.86 .{ }^{17}$

The criterion validity of the CEVQ-SF in comparison to the Childhood Trauma Questionnaire was satisfactory. ${ }^{15}$ Construct validity was shown by observing a higher odds of clinical traumatic symptoms among physically and sexually abused individuals compared with either type alone. ${ }^{15}$

Other forms of ACEs including "parental divorce or separation," "parental death" or "living with a family member with mental health problems" were assessed dichotomously. A cumulative ACEs score was created by summing the number of individual ACEs that participants have experienced and ranged from 0 to 8 . Research has shown a dose-response association between cumulative ACEs score and poor health outcomes irrespective of the type of ACEs involved. ${ }^{18-20}$

\section{Sociodemographic characteristics}

Sociodemographic characteristics included the participant's age, sex, country of birth, sexual orientation, educational attainment, annual household income and province of residence. Age was categorized as $45-54,55-64,65-74$ and $75-85$ years. Country of birth was dichotomized as participants born in Canada and those born outside of Canada. Sexual orientation was categorized as heterosexual and nonheterosexual. Selfreported highest level of education and annual household income were used as indicators of socioeconomic position. Self-reported highest level of education was categorized as no postsecondary education, postsecondary education below bachelor's degree, bachelor's degree and above, and postsecondary degree or diploma. Annual household income was categorized as less than $\$ 20000, \$ 20000-\$ 49$ 999, \$50 000-\$99999, $\$ 100000-\$ 149999$ and $\$ 150000$ and above. We reported prevalences of ACES for the subgroups described above.

\section{Statistical analysis}

Logistic regression was used to obtain the adjusted prevalence estimates of ACEs within groups formed by the sociodemographic characteristics, including age, sex, country of birth, education, household income, sexual orientation and province of residence. In this analysis, each variable was adjusted for all other sociodemographic variables. 
Prevalence estimates for province were adjusted for age and sex. Direct standardization was performed to facilitate comparison of the prevalence of ACEs across provinces and with the Canadian average. Age- and sex-stratified rates from the study sample were applied to a standard population selected as the 2015 Canadian intercensal population (Statistics Canada, https://doi.org/10.25318/1710000501-eng).

Sensitivity analysis using a "best-case" and "worse-case" scenario (all missing participants were grouped with the cases and then with the controls) was performed to explore the influence of missing data on the results. All analyses were adjusted for the sampling design and performed using inflation and analytical weights provided by the CLSA, allowing results to reflect the distribution of ACEs in the population of Canada, and were conducted using SAS v.9.4.

\section{Ethics approval}

This study was approved by the Hamilton Integrated Research Ethics Board. The ethics approval number is $7605-\mathrm{C}$.

\section{Results}

\section{Distribution of ACEs by age group and sex}

Of the total participants recruited at baseline, 44817 participants $(87.3 \%)$ completed assessments at the first follow-up between 2015 and 2018, when the ACEs questionnaire was administered. The response rate for individual ACEs questions was $97 \%$ or higher. Table 1 shows the prevalence of the 8 categories of ACEs by age group and sex. Figure 1 shows the prevalence of cumulative ACEs score by age group and sex (Appendix 1, Supplementary Table 1).

Childhood exposure to physical abuse, intimate partner violence and emotional abuse were the most prevalent types of ACEs reported across all participants. Overall, 61.6\% $(n=$ 25 933) of participants reported exposure to at least 1 ACE, and $35.6 \%$ (weighted prevalence) reported exposure to 2 or more ACEs. The results show substantial heterogeneity in the distribution of ACEs in the population. Men reported more physical abuse, whereas women reported greater exposure to

Table 1: Unadjusted weighted prevalence estimates of adverse childhood experiences by age groups and sex*

\begin{tabular}{|c|c|c|c|c|c|c|c|c|c|c|c|}
\hline Characteristic & $\begin{array}{c}\text { Total } \\
\text { sample }\end{array}$ & \multicolumn{2}{|c|}{ Total } & \multicolumn{2}{|c|}{$\begin{array}{c}\text { Age 45-54 yr } \\
\text { (birth cohort } \\
\text { 1960-1969) }\end{array}$} & \multicolumn{2}{|c|}{$\begin{array}{c}\text { Age 55-64 yr } \\
\text { (birth cohort } \\
\text { 1950-1959) }\end{array}$} & \multicolumn{2}{|c|}{$\begin{array}{c}\text { Age 65-74 yr } \\
\text { (birth cohort } \\
\text { 1940-1949) }\end{array}$} & \multicolumn{2}{|c|}{$\begin{array}{c}\text { Age } 75-85 \text { yr } \\
\text { (birth cohort } \\
\text { 1930-1939) }\end{array}$} \\
\hline$n(\%)$ & 44817 & $\begin{array}{c}21873 \\
(48.3)\end{array}$ & $\begin{array}{c}22944 \\
(51.7)\end{array}$ & $\begin{array}{c}3201 \\
(49.8)\end{array}$ & $\begin{array}{c}3397 \\
(50.2)\end{array}$ & $\begin{array}{c}6984 \\
(48.2)\end{array}$ & $\begin{array}{l}7766 \\
(51.8)\end{array}$ & $\begin{array}{c}6643 \\
(49.3)\end{array}$ & $\begin{array}{c}6660 \\
(50.8)\end{array}$ & $\begin{array}{c}5045 \\
(44.9)\end{array}$ & $\begin{array}{l}5121 \\
(55.1)\end{array}$ \\
\hline \multicolumn{12}{|c|}{ Adverse childhood experiences, no. (\%) } \\
\hline Physical abuse & $\begin{array}{l}11357 \\
(25.7)\end{array}$ & $\begin{array}{l}6580 \\
(30.0)\end{array}$ & $\begin{array}{l}4777 \\
(21.7)\end{array}$ & $\begin{array}{c}1009 \\
(30.5)\end{array}$ & $\begin{array}{c}841 \\
(26.1)\end{array}$ & $\begin{array}{l}2313 \\
(31.9)\end{array}$ & $\begin{array}{c}1914 \\
(24.4)\end{array}$ & $\begin{array}{l}2058 \\
(29.7)\end{array}$ & $\begin{array}{c}1378 \\
(20.6)\end{array}$ & $\begin{array}{c}1200 \\
(25.0)\end{array}$ & $\begin{array}{c}644 \\
(12.8)\end{array}$ \\
\hline Sexual abuse & $\begin{array}{l}7227 \\
(17.3)\end{array}$ & $\begin{array}{l}1942 \\
(9.1)\end{array}$ & $\begin{array}{l}5285 \\
(24.9)\end{array}$ & $\begin{array}{c}301 \\
(8.7)\end{array}$ & $\begin{array}{c}866 \\
(28.3)\end{array}$ & $\begin{array}{l}595 \\
(8.8)\end{array}$ & $\begin{array}{l}2015 \\
(26.5)\end{array}$ & $\begin{array}{c}633 \\
(10.0)\end{array}$ & $\begin{array}{c}1562 \\
(24.0)\end{array}$ & $\begin{array}{l}413 \\
(8.9)\end{array}$ & $\begin{array}{c}842 \\
(19.0)\end{array}$ \\
\hline Emotional abuse & $\begin{array}{l}9242 \\
(21.8)\end{array}$ & $\begin{array}{c}3960 \\
(19.1)\end{array}$ & $\begin{array}{l}5282 \\
(24.4)\end{array}$ & $\begin{array}{c}759 \\
(23.6)\end{array}$ & $\begin{array}{c}990 \\
(30.7)\end{array}$ & $\begin{array}{c}1538 \\
(22.0)\end{array}$ & $\begin{array}{l}2132 \\
(27.3)\end{array}$ & $\begin{array}{c}1147 \\
(16.4)\end{array}$ & $\begin{array}{c}1519 \\
(23.5)\end{array}$ & $\begin{array}{c}516 \\
(10.7)\end{array}$ & $\begin{array}{c}641 \\
(12.5)\end{array}$ \\
\hline $\begin{array}{l}\text { Exposure to } \\
\text { intimate } \\
\text { partner violence }\end{array}$ & $\begin{array}{l}9232 \\
(22.4)\end{array}$ & $\begin{array}{c}3977 \\
(20.1)\end{array}$ & $\begin{array}{l}5255 \\
(24.6)\end{array}$ & $\begin{array}{c}814 \\
(26.8)\end{array}$ & $\begin{array}{l}1033 \\
(31.5)\end{array}$ & $\begin{array}{l}1506 \\
(21.7)\end{array}$ & $\begin{array}{l}2065 \\
(27.3)\end{array}$ & $\begin{array}{c}1126 \\
(17.2)\end{array}$ & $\begin{array}{c}1483 \\
(22.7)\end{array}$ & $\begin{array}{c}531 \\
(12.2)\end{array}$ & $\begin{array}{c}674 \\
(13.7)\end{array}$ \\
\hline Verbal abuse & $\begin{array}{l}8631 \\
(20.9)\end{array}$ & $\begin{array}{c}3665 \\
(18.5)\end{array}$ & $\begin{array}{l}4966 \\
(23.2)\end{array}$ & $\begin{array}{c}775 \\
(25.6)\end{array}$ & $\begin{array}{c}991 \\
(30.0)\end{array}$ & $\begin{array}{c}1405 \\
(20.2)\end{array}$ & $\begin{array}{c}1970 \\
(26.0)\end{array}$ & $\begin{array}{c}1030 \\
(15.4)\end{array}$ & $\begin{array}{c}1394 \\
(21.0)\end{array}$ & $\begin{array}{c}455 \\
(10.5)\end{array}$ & $\begin{array}{c}611 \\
(12.7)\end{array}$ \\
\hline $\begin{array}{l}\text { Physical } \\
\text { violence }\end{array}$ & $\begin{array}{c}3265 \\
(7.8)\end{array}$ & $\begin{array}{l}1389 \\
(6.5)\end{array}$ & $\begin{array}{l}1876 \\
(9.0)\end{array}$ & $\begin{array}{l}268 \\
(8.0)\end{array}$ & $\begin{array}{c}337 \\
(10.8)\end{array}$ & $\begin{array}{l}495 \\
(6.9)\end{array}$ & $\begin{array}{c}761 \\
(10.1)\end{array}$ & $\begin{array}{l}427 \\
(6.1)\end{array}$ & $\begin{array}{l}540 \\
(9.1)\end{array}$ & $\begin{array}{c}199 \\
(4.3)\end{array}$ & $\begin{array}{l}238 \\
(4.4)\end{array}$ \\
\hline $\begin{array}{l}\text { Death of a } \\
\text { parent }\end{array}$ & $\begin{array}{c}7264 \\
(16.3)\end{array}$ & $\begin{array}{c}3477 \\
(15.6)\end{array}$ & $\begin{array}{l}3787 \\
(17.0)\end{array}$ & $\begin{array}{c}385 \\
(11.7)\end{array}$ & $\begin{array}{c}435 \\
(14.3)\end{array}$ & $\begin{array}{c}1008 \\
(15.6)\end{array}$ & $\begin{array}{c}1194 \\
(15.1)\end{array}$ & $\begin{array}{c}1066 \\
(15.7)\end{array}$ & $\begin{array}{c}1162 \\
(19.5)\end{array}$ & $\begin{array}{c}1018 \\
(20.5)\end{array}$ & $\begin{array}{c}996 \\
(20.3)\end{array}$ \\
\hline $\begin{array}{l}\text { Parental divorce } \\
\text { or separation }\end{array}$ & $\begin{array}{l}4298 \\
(10.7)\end{array}$ & $\begin{array}{c}2016 \\
(10.7)\end{array}$ & $\begin{array}{l}2282 \\
(10.8)\end{array}$ & $\begin{array}{c}526 \\
(16.1)\end{array}$ & $\begin{array}{c}592 \\
(17.5)\end{array}$ & $\begin{array}{c}744 \\
(11.9)\end{array}$ & $\begin{array}{c}909 \\
(11.6)\end{array}$ & $\begin{array}{l}432 \\
(7.0)\end{array}$ & $\begin{array}{l}466 \\
(7.8)\end{array}$ & $\begin{array}{l}314 \\
(6.9)\end{array}$ & $\begin{array}{l}315 \\
(6.1)\end{array}$ \\
\hline
\end{tabular}




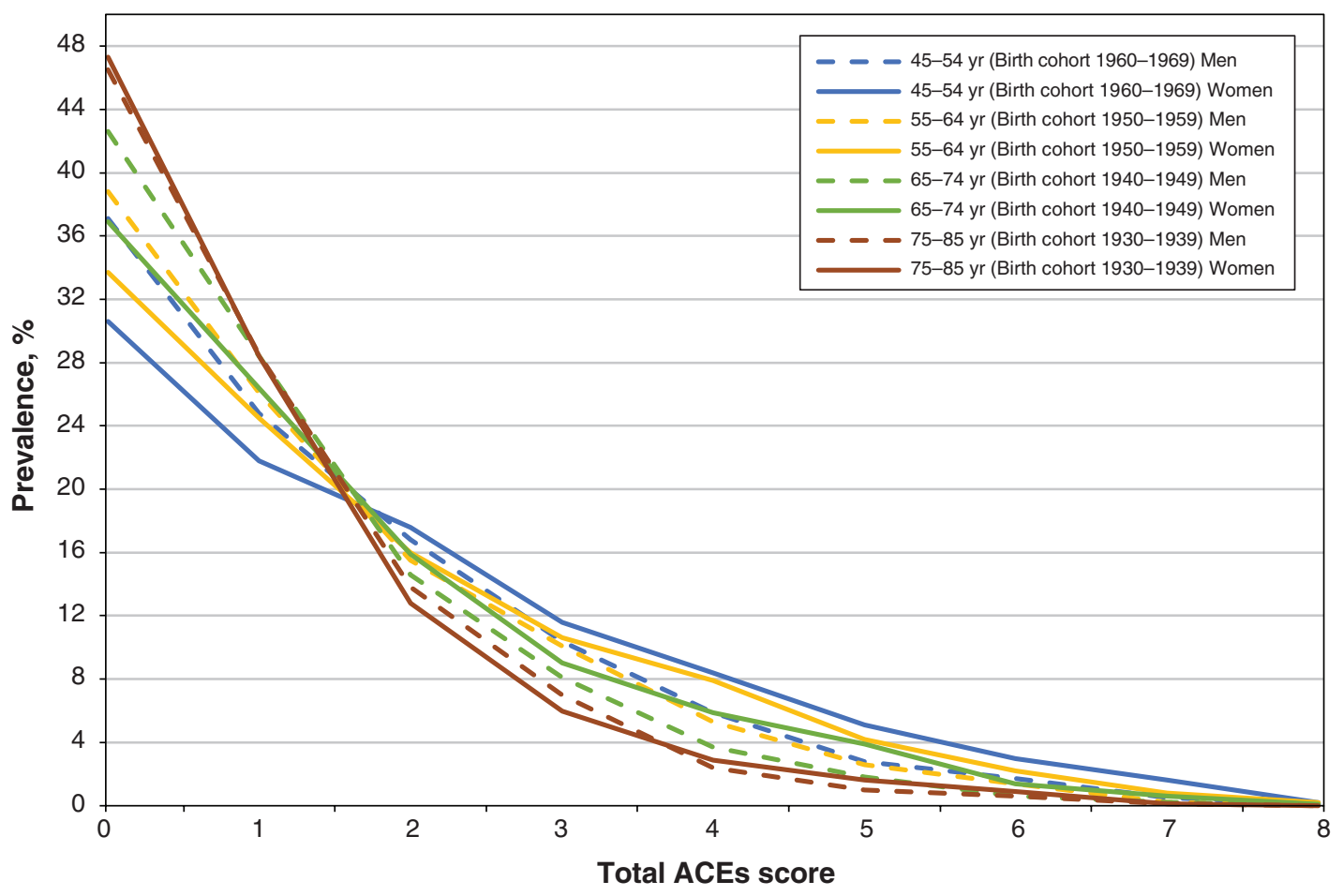

Figure 1: Weighted prevalence for total adverse childhood experiences (ACEs) score by age and sex groups.

sexual and emotional abuse, neglect, intimate partner violence and living with a family member with mental health problems. A greater proportion of women (weighted prevalence 13.4\%) compared with men $(8.2 \%)$ reported experiencing 4 or more ACEs. The results obtained from adjusted analyses examining the distribution of ACEs by participant characteristics are presented in Figures 2, 3, 4, 5 and 6.

The prevalence of ACEs was negatively associated with increasing age group. Individuals in the oldest age group (1930-1939 birth cohort) reported the least exposure to all ACEs with the exception of experiencing death of a parent compared with the younger age groups. In contrast, individuals younger than 65 years (1950-1969 birth cohort) reported greater exposure to physical and emotional abuse, intimate partner violence, parental divorce or separation and living with a family member with mental health problems.

\section{Distribution of ACEs by socioeconomic factors and sexual orientation}

In addition to age and sex, socioeconomic factors and sexual orientation were important factors associated with exposure to ACEs (Figures 3, 4 and 5). Socioeconomic deprivation in adulthood was associated with a higher prevalence of all types of ACEs. Individuals with no postsecondary education or education below a bachelor's degree had higher prevalence of all ACEs except parental death compared with individuals who had obtained at least a bachelor's degree. Similarly, individuals who had household income less than $\$ 20000$ had higher prevalence of all ACEs except parental death compared with those with an annual income of at least $\$ 50000$. With respect to sexual orientation, exposure to sexual and emotional abuse, intimate partner violence and living with a family member with poor mental health were higher among individuals of nonheterosexual orientation compared with individuals of heterosexual orientation. The difference among groups was more prominent for exposure to sexual abuse, emotional abuse and intimate partner violence.

\section{Distribution of ACEs by province}

Figure 7 shows the within-sample age and sex-adjusted prevalence of ACEs for each province (Appendix 1, Supplementary Table 2). Overall, British Columbia reported higher prevalence for several examined categories of ACEs. Reporting for some ACEs was also higher for Alberta, Manitoba, Ontario and Quebec. Next, we performed direct standardization to eliminate age- and sex-related differences in the population to facilitate comparison of prevalence estimates among provinces (results not reported). Although the estimates changed to some extent, the overall trends after standardization were similar to the values obtained from withinsample age and sex adjustment with a few exceptions. After standardization, prevalence of exposure to emotional abuse and intimate partner violence was higher in Alberta, and neglect was higher in Prince Edward Island. Results of a sensitivity analysis using a "best-case" and "worse-case" scenario (all missing participants were grouped with the cases and then with the controls) did not differ from the final results reported in the study. 


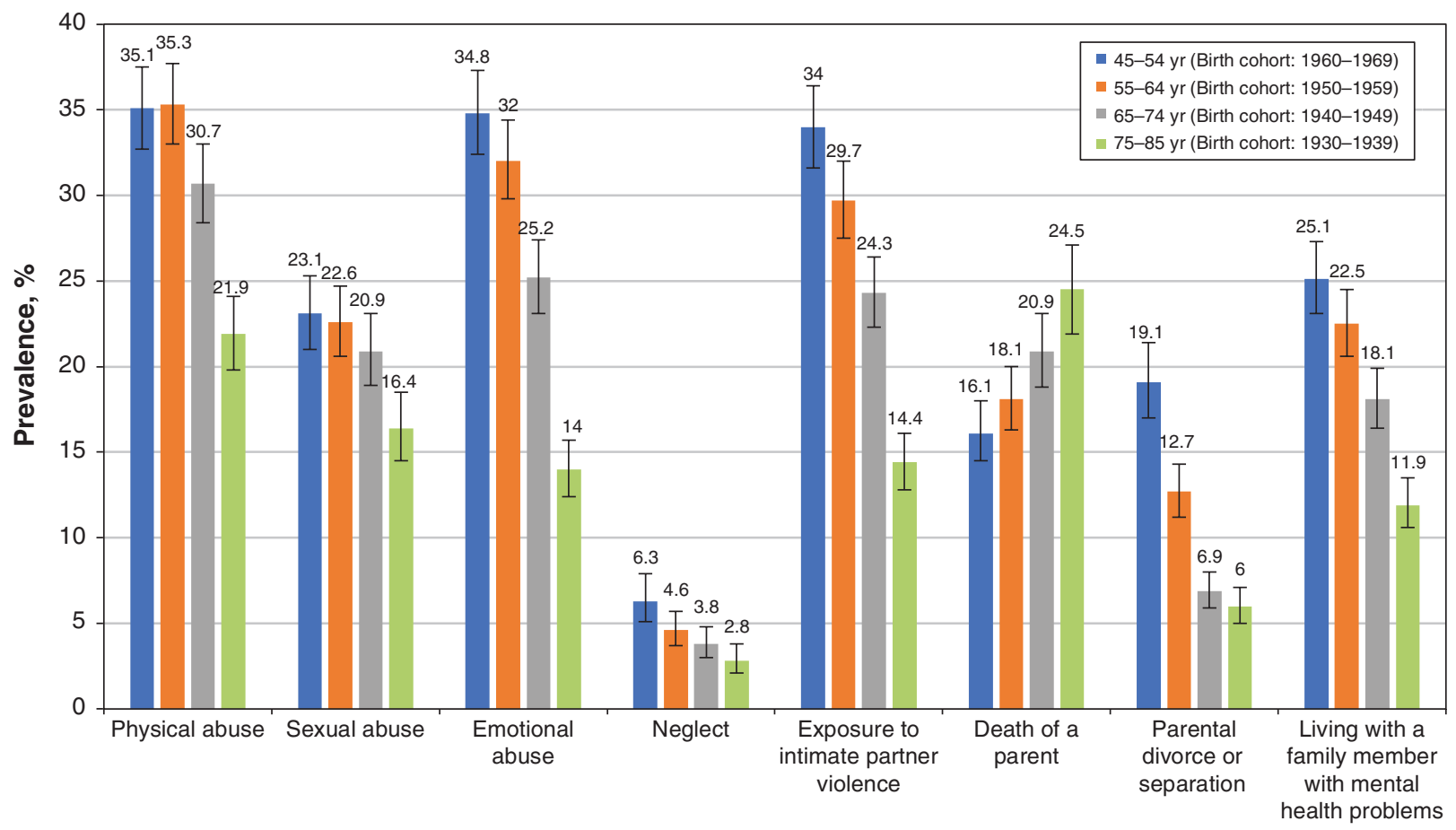

Adverse childhood experiences

Figure 2: Adjusted weighted prevalence for adverse childhood experiences by age groups. The error bars represent $95 \%$ confidence intervals for the weighted prevalence estimates.

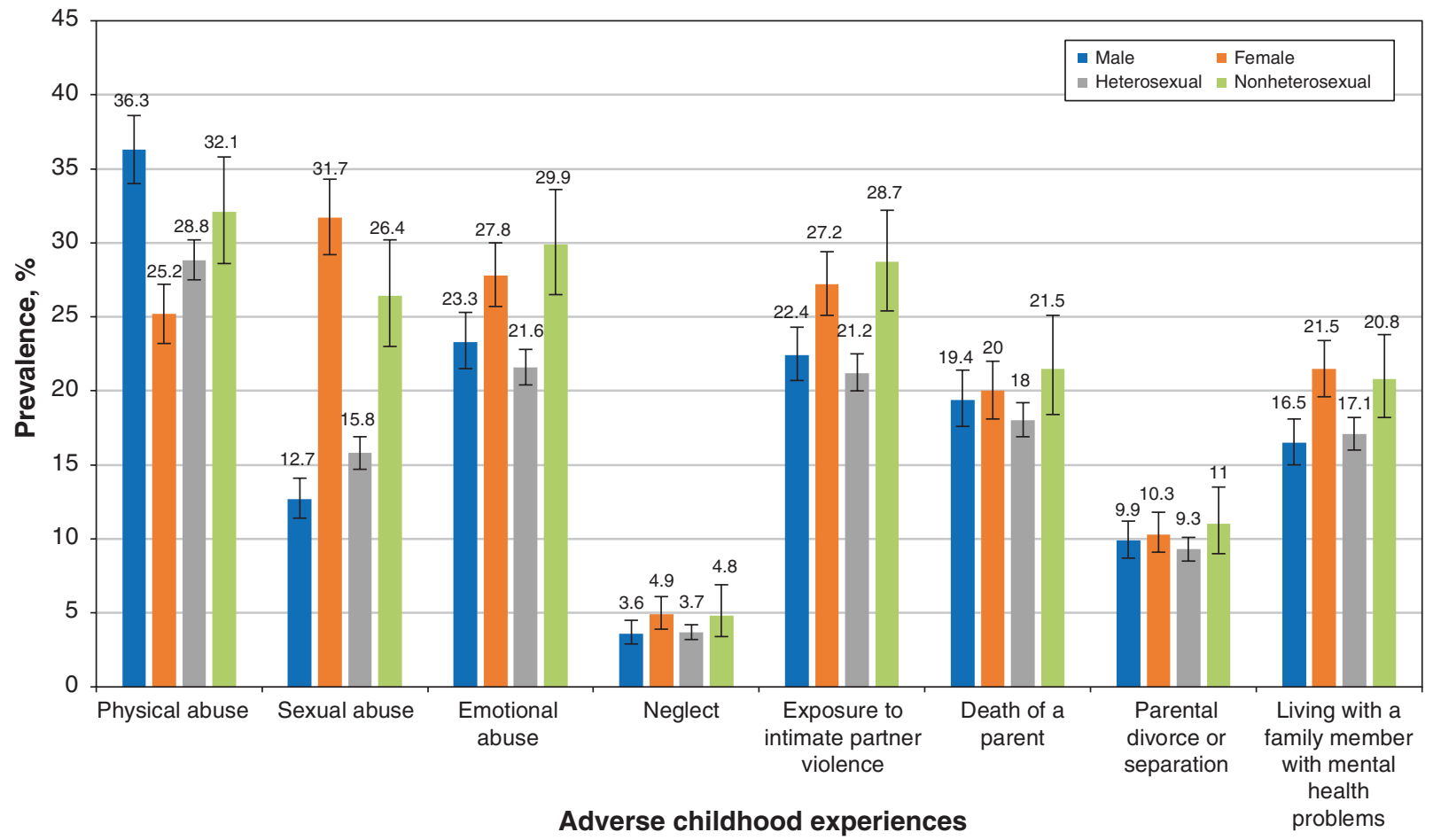

Figure 3: Adjusted weighted prevalence for adverse childhood experiences by sex and sexual orientation groups. The error bars represent $95 \%$ confidence intervals for the weighted prevalence estimates. 


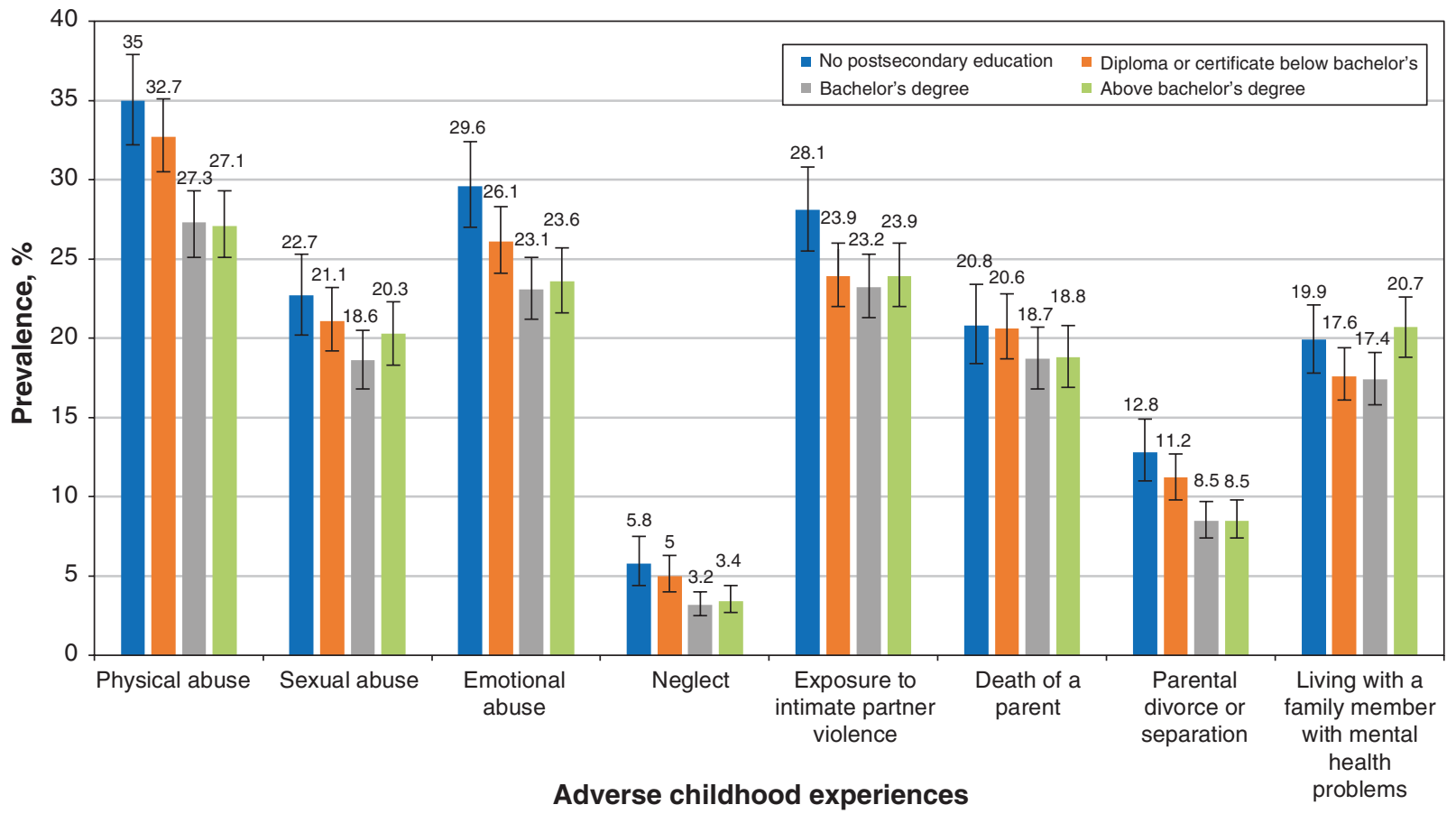

Figure 4: Adjusted weighted prevalence for adverse childhood experiences by highest level of education attained. The error bars represent $95 \%$ confidence intervals for the weighted prevalence estimates.

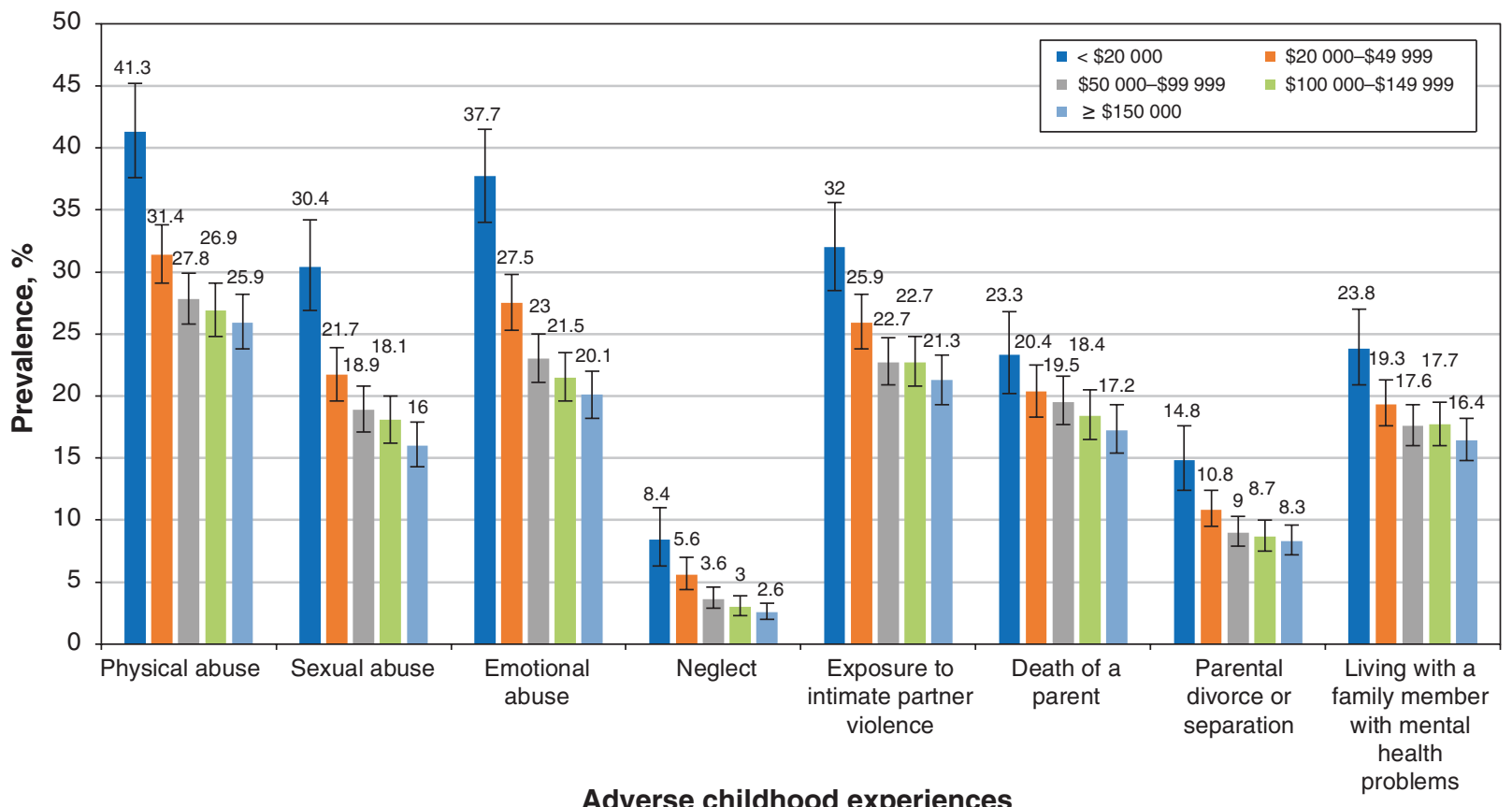

Figure 5: Adjusted weighted prevalence for adverse childhood experiences by total annual household income groups. The error bars represent $95 \%$ confidence intervals for the weighted prevalence estimates. 


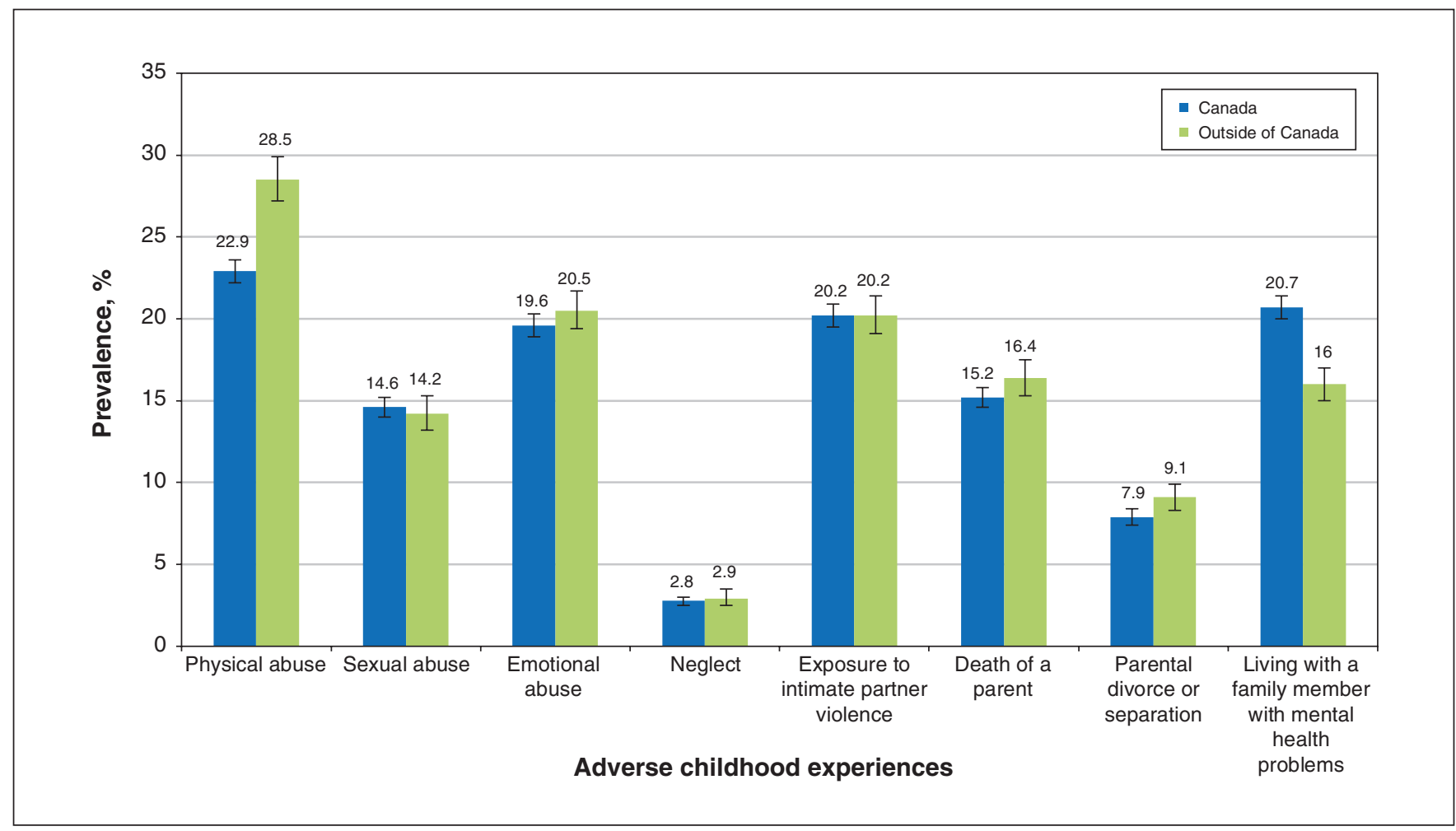

Figure 6: Adjusted weighted prevalence for adverse childhood experiences by country of birth. The error bars represent $95 \%$ confidence intervals for the weighted prevalence estimates.

\section{Interpretation}

We found that ACEs were highly prevalent across all demographic groups, although some groups in the population experienced an unequal and greater burden. Our findings are consistent with the prevalence estimates and time trends reported in other Canadian studies. Canadian statistics have estimated the prevalence of exposure to physical abuse to be $26 \%$, sexual abuse to be between $7 \%$ and $15 \%$, emotional abuse to be between $14 \%$ and $17 \%$, intimate partner violence to be between $6 \%$ and $26 \%$, parental divorce or separation to be between $11 \%$ and $17.6 \%$, and poor parental mental health to be $20.6 \% ., 5,21-26$ Estimates reported in our study are within the range reported in the literature with the exception of sexual and emotional abuse, which are reported at higher rates here.

Further, we found that people born in 1950-1969 (ages 45-64) reported higher ACEs compared with those born before 1950 (ages 65 and older), and reporting for ACEs, with the exception of parental death, was lowest among those born in 1930-1939 (ages 75-85). These results are consistent with other Canadian data. Analysis of the 2012 CCHS data found that reporting of exposure to physical abuse, sexual abuse or intimate partner violence was elevated among respondents from the 1943-1982 birth cohort, especially among individuals born between 1953 and 1972, and lower in those born in or before 1942 when compared with the 1983-1992 birth cohort. ${ }^{5,25,26}$ Similarly, results from the Canadian component of the GENACIS project (Gender, alcohol and culture: an international study) showed that child sexual abuse rates declined after 1993 but were significantly higher between 1946 and 1992 compared with the period before 1946. ${ }^{26,27}$

The reasons for higher reporting of ACEs among the 19501969 birth cohort in our study is unclear, but examining the trauma and disruptions after World War II may help to explain these time trends. ${ }^{26}$ It is also possible that the reporting of ACEs may be affected by secular trends. ${ }^{26}$ Younger individuals may be more likely to acknowledge and report maltreatment as an effect of increased media coverage, whereas lower reporting among older individuals may be because of their reluctance to disclose experiences, which may be viewed as stigmatizing during the period in which they were born. ${ }^{25-28}$ In addition, prevalence in the oldest age group may be influenced by premature mortality experienced by individuals exposed to ACEs. ${ }^{29}$

Our findings showed that exposure to ACEs varied across Canadian provinces. Generally, higher proportions of maltreatment and household adversities were reported for BC, Alberta, Manitoba, Ontario and Quebec. These findings are consistent with results presented from the CCHS, which reported child abuse rates to be lower in Newfoundland and Labrador and higher in the Prairie region and BC. ${ }^{5,25}$ However, further research is required to evaluate and understand the observed heterogeneity among provinces.

We found that individuals who have education below a bachelor's degree and those with lower annual household income reported greater exposure to ACEs, suggesting that early life adversity negatively affects educational attainment 


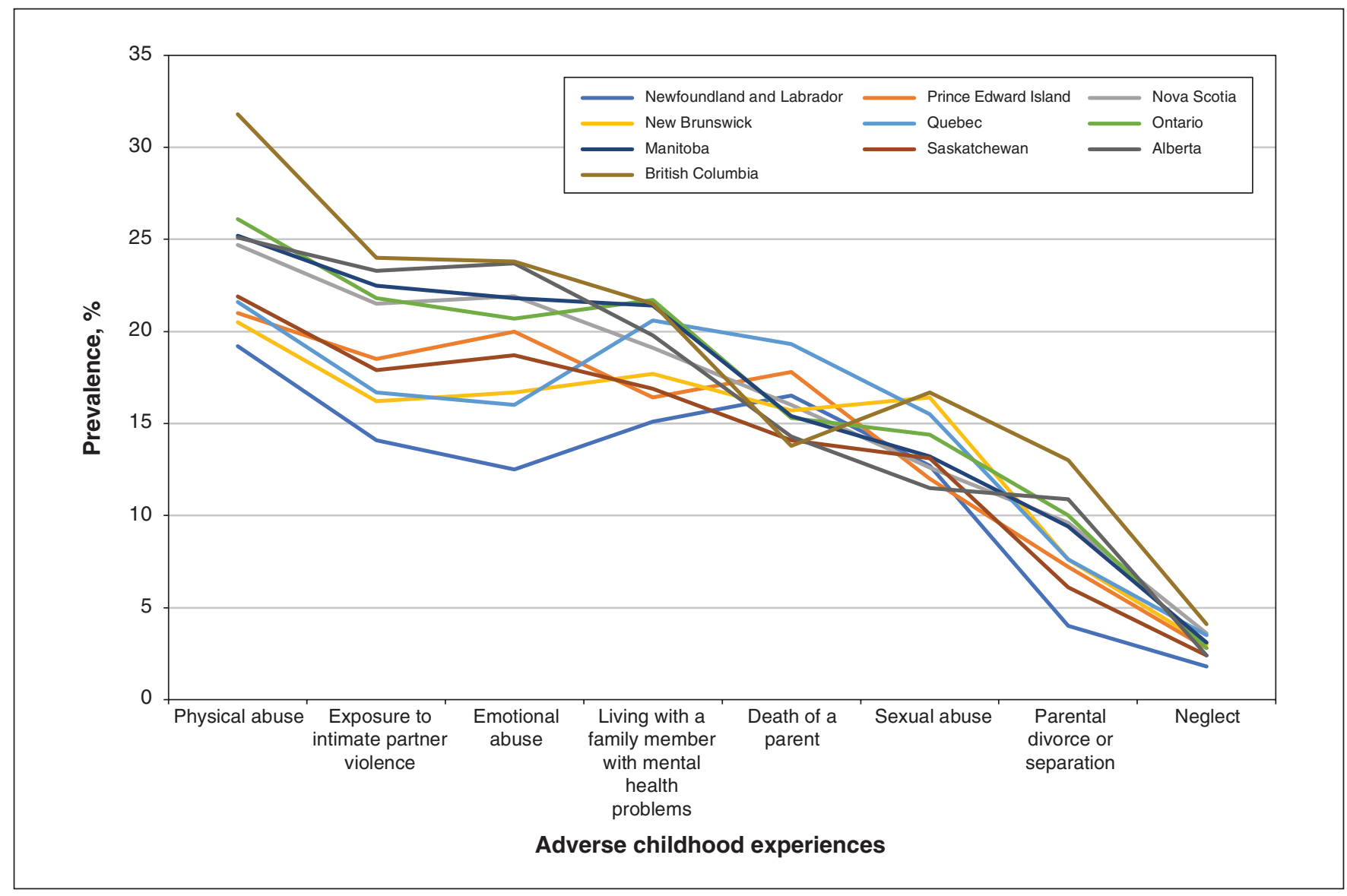

Figure 7: Adjusted weighted prevalence for adverse childhood experiences by province.

and income later in life. Low educational attainment and income are interrelated, and, in addition to their known impacts on physical and psychological health and well-being, they also affect future generations. ${ }^{30,31}$ Further, consistent with the literature, our results showed that nonheterosexual participants reported increased exposure to many ACEs. Previous research suggested that adolescents who reported nonheterosexual orientation were at greater risk of being maltreated. ${ }^{32}$ In addition, gender nonconforming behaviours are often recognized by adults much before a child is aware of his or her sexual identity; it is possible that adults may have used maltreatment to repress these behaviours or other indications of sexual minority status. ${ }^{33,34}$ Further, in households experiencing dysfunction, a child with atypical gender appearance and behaviour may be at a greater risk of being targeted for abuse. . $3,35^{3}$

Strategies that increase awareness of ACEs and their longlasting consequences, support positive parenting, promote healthy child development and improve overall quality of household environments are needed to prevent exposure to childhood adversity. In addition, trauma-informed approaches need to be developed and promoted to assist individuals affected by ACEs. Clinicians can play an important role by being cognizant about ACEs and implementing traumainformed care to alleviate the harms caused by ACEs. Future research should evaluate the association between ACEs and health outcomes, including morbidity and functioning, and test the pathways that may explain the impact of childhood adversity on long-term health outcomes.

\section{Limitations}

This study has limitations that should be considered when interpreting the findings. Exposure to ACEs was reported retrospectively and may be prone to recall and reporting biases. However, studies have reported good test-retest reliability for individual questions and for the overall ACEs score..$^{15,17}$ In addition, emotional abuse and neglect were each assessed using a single question and did not distinguish among subtypes of neglect. Furthermore, sexual orientation was categorized as heterosexual and nonheterosexual because of small cell sizes. It is also possible that the prevalence rates of ACEs were underestimated given that the study sample did not include individuals residing on First Nation reserves, territories and institutions, and that the CLSA participants, on average, have higher education and household income.

Nevertheless, this study included a large, nationally generalizable sample of participants and evaluated 8 different forms of ACEs including emotional abuse and neglect. Comparisons of the sociodemographic characteristics of the CLSA participants with those of the CCHS-Healthy Aging and the Statistics Canada Census 2011 suggest that the results obtained from this study are generalizable to the comparable Canadian population on many key variables including age, sex, marital status, urban-rural dwelling and working status. ${ }^{13}$ 


\section{Conclusion}

Overall, our results indicate that ACEs, a serious public health concern, are highly prevalent in Canada. Effective approaches that integrate recognition and prevention are required to reduce the burden of ACEs. Further, future research is necessary to understand why certain subgroups in the population are at a greater risk than others of experiencing ACEs and how this may contribute to health disparities across the lifespan.

\section{References}

1. Felitti VJ, Anda RF, Nordenberg D, et al. Relationship of childhood abuse and household dysfunction to many of the leading causes of death in adults: the Adverse Childhood Experiences (ACE) study. Am 7 Prev Med 1998;14:245-58.

2. Felitti VJ, Anda RF, Nordenberg D, et al. Relationship of childhood abuse and household dysfunction to many of the leading causes of death in adults: the Adverse Childhood Experiences (ACE) study. Am F Prev Med 2019;56:774-86.

3. Hughes K, Bellis MA, Hardcastle KA, et al. The effect of multiple adverse childhood experiences on health: a systematic review and meta-analysis. Lancet Public Health 2017;2:e356-66.

4. Gonzalez A, Boyle MH, Kyu HH, et al. Childhood and family influences on depression, chronic physical conditions, and their comorbidity: findings from the Ontario Child Health Study. F Psychiatr Res 2012;46:1475-82.

5. Afifi TO, MacMillan HL, Boyle M, et al. Child abuse and mental disorders in Canada. CMA7 2014;186:E324-32.

6. Guedes DT, Vafaei A, Alvarado BE, et al. Experiences of violence across life course and its effects on mobility among participants in the International Mobility in Aging study. BM7 Open 2016;6:e12339.

7. Danese A, McEwen BS. Adverse childhood experiences, allostasis, allostatic load, and age-related disease. Physiol Behav 2012;106:29-39.

8. England-Mason G, Casey R, Ferro M, et al. Child maltreatment and adult multimorbidity: results from the Canadian Community Health Survey. Can 7 Public Health 2018;109:561-72.

9. Bowling A, Dieppe P. What is successful ageing and who should define it? BM7 2005;331:1548-51.

10. Bellis M, Hughes K, Hardcastle K, et al. The impact of adverse childhood experiences on health service use across the life course using a retrospective cohort study. 7 Health Serv Res Policy 2017;22:168-77.

11. Fang X, Brown DS, Florence CS, et al. The economic burden of child maltreatment in the United States and implications for prevention. Cbild Abuse Negl 2012;36:156-65

12. Raina PS, Wolfson C, Kirkland SA, et al. The Canadian longitudinal study on aging (CLSA). Can F Aging 2009;28:221-9.

13. Raina P, Wolfson C, Kirkland S, et al. Cohort profile: The Canadian Longitudinal Study on Aging (CLSA). Int 7 Epidemiol 2019;48:1752-1753j.

14. Walsh CA, MacMillan HL, Trocmé N, et al. Measurement of victimization in adolescence: development and validation of the Childhood Experiences of Violence questionnaire. Child Abuse Negl 2008;32:1037-57.

15. Tanaka M, Wekerle C, Leung E, et al. Preliminary evaluation of the Childhood Experiences of Violence Questionnaire short form. 7 Interpers Violence 2012:27:396-407.

16. Harris KM, Udry JR. National Longitudinal Study of Adolescent to Adult Health 1994-2008. Chapel Hill (NC): Carolina Population Center, University of North Carolina-Chapel Hill, Inter-university Consortium for Political and Social Research; 2014.

17. Dube SR, Williamson DF, Thompson T, et al. Assessing the reliability of retrospective reports of adverse childhood experiences among adult HMO members attending a primary care clinic. Child Abuse Negl 2004;28:729-37.

18. Merrick MT, Ports KA, Ford DC, et al. Unpacking the impact of adverse childhood experiences on adult mental health. Child Abuse Negl 2017;69:10-9.

19. Voellmin A, Winzeler K, Hug E, et al. Blunted endocrine and cardiovascular reactivity in young healthy women reporting a history of childhood adversity. Psychoneuroendocrinology 2015;51:58-67.

20. Gilbert LK, Breiding MJ, Merrick MT, et al. Childhood adversity and adult chronic disease: an update from ten states and the District of Columbia, 2010. Am 7 Prev Med 2015;48:345-9.

21. McDonald S, Kingston D, Bayrampour H, et al. Adverse childhood experiences in Alberta, Canada: a population-based study. Med Res Arch 2015;3:1-18.

22. Afifi TO, MacMillan HL, Boyle M, et al. Child abuse and physical health in adulthood. Health Rep 2016;27:10-8.

23. Langlois KA, Garner R. Trajectories of psychological distress among Canadian adults who experienced parental addiction in childhood. Health Rep 2013;24:14-21.

24. Maltreatment in Canada. Ottawa: Public Health Agency of Canada; 2011. Available: www.canada.ca/en/public-health/services/health-promotion/stop -family-violence/prevention-resource-centre/children/child-maltreatment -canada.html (accessed 2020 Mar. 31).
25. Ligier F, Giguère CÉ, Seguin $M$, et al. Survey evidence of the decline in child abuse in younger Canadian cohorts. Eur 7 Pediatr 2019;178:1423-32.

26. Shields M, Tonmyr L, Hovdestad W. Is child sexual abuse declining in Canada? Results from nationally representative retrospective surveys. Policy Pract 2016;36:252-60.

27. Shields M, Tonmyr L, Hovdestad WE. The decline of child sexual abuse in Canada: evidence from the 2014 General Social survey. Can $\mathcal{F}$ Psychiatry 2019;64:638-46.

28. Weatherred JL. Child sexual abuse and the media: a literature review. 7 Cbild Sex Abus 2015;24:16-34

29. Brown DW, Anda RF, Tiemeier H, et al. Adverse childhood experiences and the risk of premature mortality. Am 7 Prev Med 2009;37:389-96.

30. Chevalier A, Harmon C, O'Sullivan V, et al. The impact of parental income and education on the schooling of their children. IZA 7 Labor Econ 2013;2:8-30.

31. Erola J, Jalonen S, Lehti H. Parental education, class and income over early life course and children's achievement. Res Soc Stratif Mobil 2016;44:33-43.

32. Andersen JP, Blosnich J. Disparities in adverse childhood experiences among sexual minority and heterosexual adults: Results from a multi-state probability-based sample. PLoS One 2013;8:e54691.

33. D'Augelli AR, Grossman AH, Starks MT. Childhood gender atypicality, victimization, and PTSD among lesbian, gay, and bisexual youth. 7 Interpers Violence 2006;21:1462-82.

34. Goodrich KM. Mom and dad come out: The process of identifying as a heterosexual parent with a lesbian, gay, or bisexual child. 7 LGBT Issues Couns 2009;3:37-61.

35. Alvy LM, Hughes TL, Kristjanson AF, et al. Sexual identity group differences in child abuse and neglect. F Interpers Violence 2013;28:2088-111.

Affiliations: Department of Health Research Methods, Evidence, and Impact (Joshi, Raina), McMaster University; McMaster Institute for Research on Aging (Raina), Hamilton, Ont.; Public Health Agency of Canada (Tonmyr), Ottawa, Ont.; Department of Sociology and Anthropology (Tonmyr), Carleton University, Ottawa, Ont.; Department of Pediatrics (MacMillan) and of Psychiatry and Behavioural Neurosciences (MacMillan, Gonzalez), McMaster University; Offord Centre for Child Studies (Gonzalez), Hamilton, Ont.

Contributors: Divya Joshi, Andrea Gonzalez and Parminder Raina contributed to the original conception, design and analysis of the work. Divya Joshi and Andrea Gonzalez drafted the manuscript. All of the authors contributed to interpretation of the data, critically revised the manuscript for important intellectual content, gave final approval of the version to be published and agreed to be accountable for all aspects of the work.

Funding: The Canadian Longitudinal Study on Aging (CLSA) is funded by the Canadian Institutes of Health Research (CIHR) and the Canada Foundation for Innovation. This analysis was supported by McMaster Institute for Research on Aging. Parminder Raina holds a Tier 1 Canada Research Chair in Geroscience and the Raymond and Margaret Labarge Chair in Research and Knowledge Application for Optimal Aging. Andrea Gonzalez holds a Tier 2 Canada Research Chair in Family Health and Preventive Interventions. Harriet MacMillan is supported by the Chedoke Health Chair in Child Psychiatry.

Content licence: This is an Open Access article distributed in accordance with the terms of the Creative Commons Attribution (CCBYNCND 4.0) licence, which permits use, distribution and reproduction in any medium, provided that the original publication is properly cited, the use is noncommercial (i.e., research or educational use), and no modifications or adaptations are made. See: https://creativecommons. org/licenses/by-nc-nd/4.0/

Data sharing: Data are available from the CLSA (www.clsa-elcv.ca) for researchers who meet the criteria for access to deidentified CLSA data.

Acknowledgements: This research was made possible using the data and biospecimens collected by the CLSA. Funding for the CLSA is provided by the Government of Canada through the CIHR under grant reference LSA 94473 and the Canada Foundation for Innovation. This research has been conducted using the Baseline Tracking Dataset version 3.4, Comprehensive Dataset version 4.0, Follow-up 1 Tracking Dataset version 1.0, under Application Number 190230. The CLSA is led by Drs. Parminder Raina, Christina Wolfson and Susan Kirkland.

Supplemental information: For reviewer comments and the original submission of this manuscript, please see www.cmajopen.ca/content/9/1/ E158/suppl/DC1. 